\title{
Aplicação de Mapa Auto-Organizável ao Agrupamento de Dados de Refletividade de Radar
}

\author{
Jorge V. R. Bonato, Paulo H. Siqueira, \\ Programa de Pós-Graduação em Métodos Numéricos, CESEC, UFPR, \\ 81531-970, Curitiba, PR \\ E-mail: bonato.ruviaro@gmail.com, paulohs@gmail.com, \\ Cesar A. A. Beneti \\ Instituto Tecnológico Simepar \\ 81531-980, Curitiba, PR \\ E-mail: beneti@simepar.br.
}

\begin{abstract}
Resumo: A clusterização busca organizar grandes volumes de dados em subgrupos menores, de maneira a facilitar sua análise. Ao aplicá-la em dados meteorológicos de refletividade deseja-se agrupar os dados de maneira a formar grupos representando nuvens. Nesse trabalho usou-se a Rede Neural Artificial SOM de Kohonen.
\end{abstract}

Palavras-chave: Rede Neural Artificial, Meteorologia, Agrupamentos

\section{Introdução}

A clusterização de dados é importante ferramenta utilizada à análise de dados em grande volume. É também utilizada na meteorologia quando, por exemplo, se deseja clusterizar dados de refletividade de radar, para posterior aplicação em técnicas de previsão de desenvolvimento e deslocamento de eventos severos. Em [7] apresenta-se a técnica de nowcasting ForTraCC, na qual a clusterização se dá através da identificação de pixels contíguos, pertencentes a dado intervalo, que passam então por dilatação e erosão matemáticas. Outras técnicas podem ser vistas em [4] e [6].

Neste trabalho aplicou-se a Rede Neural Artificial, de aprendizado não-supervisionado, SOM (Self-OrganizingMaps) de Kohonen para clusterizar dados de refletividade vindos de um dos radares do Instituto Tecnológico Simepar, instalado em Teixeira Soares - PR e que atualmente opera com alcances quantitativo e qualitativo, respectivamente de $480 \mathrm{Km}$ e $240 \mathrm{Km}$.

\section{Objetivos}

O presente trabalho tem por objetivo agrupar dados de radar, em especial os referentes a refletividade, de maneira a gerar núcleos de dados para posterior aplicação à métodos de previsão de desenvolvimento de eventos severos, entre eles o apresentado em [7].

\section{Dados}

Radares meteorológicos possuem 4 componentes principais, sendo eles o transmissor, a antena, o receptor e um display. Seu funcionamento se dá da seguinte maneira: o transmissor emite um sinal eletromagnético, que é direcionado à atmosfera pela antena. Ao atingir uma partícula, parte do sinal é refletido em direção ao receptor do radar e então pode ser visualizado no display. 
A partir da detecção de uma partícula, sua posição é dada através da tripla $(\theta, r, \phi)$, sendo $\theta$ o ângulo de azimute (ângulo em relação ao Norte), $r$ a distância partícula-radar e $\phi$ o ângulo de elevação da antena (em relação ao solo).

Uma das variáveis passíveis de serem medidas através do uso de radares meteorológicos é chamada de fator refletividade, que está relacionada à quantidade de energia que retorna ao radar após a onda eletromagnética emitida pelo radar atingir um alvo na atmosfera. Esta variável é denotada por $z$ e definida como:

$$
z=\sum_{i=1}^{N} D_{i}^{6}
$$

sendo $N$ o número de partículas presente na amostra do volume em análise.

Para fins de ilustração segue a figura 1, na qual há presença de 16 partículas com diferentes raios:

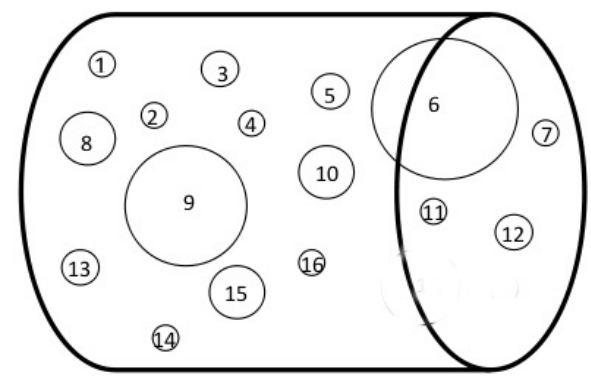

Figura 1: Ilustração de volume com distribuição de gotas

Como pode ser ver em (1) o fator refletividade é proporcional à sexta potência do diâmetro das partículas, podendo variar de pequenos a grandes valores no casos de, respectivamente, névoa e tempestades. De maneira a facilitar seu uso e análise faz-se necessário alterar a escala, de linear para logarítmica, através da seguinte transformação:

$$
Z=10 \log _{10}\left(\frac{z}{1 m m^{6} / m^{3}}\right)
$$

Ao fim desse processo tem-se que a variável refletividade é media em decibéis de refletividade $(d B Z)$.

Segundo [5] os dados volumétricos de radar são geralmente obtidos através da rotação da antena em torno de um eixo vertical, para diferentes ângulos de elevação. Após cada varredura volumétrica tem-se uma matriz de dados em coordenadas polares, que antes de aplicados à rede neural passam por um processo de mudança de coordenadas para o sistema cartesiano, nesse caso com resolução de $0.5 \mathrm{Km}$ x $0.5 \mathrm{Km}$ x $0.5 \mathrm{Km}$, obtendo assim uma matriz de dimensão $(480,480,30)$. Para cada coluna da matriz de dados cartesiana determinou-se o valor de máxima refletividade, gerando assim uma matriz de dimensão $(480,480)$, que então foi aplicada à rede.

Neste trabalho definiu-se tempestade através dos seguintes passos:

- Identificação de pontos tais que seu valor de refletividade pertenciam ao intervalo entre 30 e $60 d B Z$;

- Busca de regiões contíguas formadas por pontos identificados acima, tais que sua área seja superior a $20 \mathrm{Km}^{2}$

O período de dados utilizados para esse estudo compreende os 12 meses, entre Setembro de 2011 e Setembro de 2012 . 


\section{Metodologia}

Desenvolvida por [3], a Rede Neural Artificial Mapa de Kohonen possui aprendizado nãosupervisionado baseado na competição dos neurônios, cujo principal objetivo é transformar padrões de entrada com dimensão arbitrária em mapas uni ou bi-dimensional. Seu algoritmo genérico é mostrado a seguir:

1. Inicialização: escolha de valores aleatórios para os pesos sinápticos iniciais;

2. Amostragem: aplica-se à rede um vetor de entrada $x$ pertencente ao conjunto de dados;

3. Combinação por similaridade: determina-se o neurônio BMU (Best Matching Unit), com base em uma função discriminante;

4. Atualização: pesos sinápticos do neurônio vencedor e daqueles pertencentes à sua vizinhança topológica são atualizados;

5. Continuação: repete-se os passos 2,3 e 4 até não haver alterações significativas;

\subsection{Inicialização}

A primeira etapa a ser realizada antes de iniciar o agrupamento dos dados é determinar quais características melhor definem cada grupo, além de escolher uma função discriminante para medir a similaridade entre dados de entrada e os neurônios da rede. Nesse trabalho optou-se por fazer uso do vetor $\left(i, j, Z_{i j}\right)$, sendo $(i, j)$ a posição da matriz de dados e $Z_{i j}$ seu respectivo valor de refletividade. A escolha de uma grade com 25 neurônios se deve ao fato de ser pequena a probabilidade de haver um número maior de grupos em uma imagem de radar.

A inicialização dos pesos sinápticos foi feita escolhendo, de maneira aleatória, valores para $i$ e $j$ no intervalo de 0 a 479 , e então buscou-se o valor $Z_{i j}$ na matriz de dados. Segundo [1], a normalização dos dados de entrada e dos pesos sinápticos leva a uma melhoria na convergência, assim determinou-se:

$$
i^{*}=\frac{i}{479} \quad j^{*}=\frac{j}{479} \quad Z_{i j}^{*}=\frac{Z_{i j}}{\max (Z)}
$$

\subsection{Combinação por Similaridade}

Após definido o número de neurônios e características a serem analisadas, e inicialização dos vetores de pesos sinápticos de cada padrão de entrada e neurônio têm, respectivamente, as formas:

$$
\mathrm{x}=\left[\begin{array}{lll}
i^{*} & j^{*} & Z_{i j}^{*}
\end{array}\right]^{T} \quad \mathrm{w}_{k}=\left[\begin{array}{lll}
w_{k}^{1} & w_{k}^{2} & w_{k}^{3}
\end{array}\right]^{T}
$$

Como função discriminante usou-se o quadrado da distância Euclidiana:

$$
D\left(x, w_{k}\right)=\sum_{l=1}^{3}\left(x^{l}-w_{k}^{l}\right)^{2}
$$

O neurônio vencedor ou BMU (Best Matching Unit) é o neurônio tal que a equação 5 possua valor mínimo.

\subsection{Atualização}

O $B M U$ define o centro da vizinhança topológica, formada por neurônios que também terão seus pesos sinápticos atualizados. A função vizinhança deve possuir valor máximo no neurônio vencedor e decrescimento monótono com o aumento da distância ao neurônio vencedor. Considerando $d_{i j}$ a distância entre o $B M U$ e um neurônio $j$ pertencente à vizinhança topológica então define-se a função vizinhança $h_{i j}$ : 


$$
h_{i j}=e^{\frac{-d_{i j}^{2}}{2 \sigma^{2}}}
$$

sendo $\sigma$ o raio da vizinhança topológica, que também é atualizado a cada iteração. Seguindo o que é apresentado em [2] fez-se uso do decaimento exponencial como atualizador do raio da vizinhança:

$$
\sigma(t)=\sigma_{0} e^{\frac{-t}{\tau_{1}}}
$$

sendo $\sigma_{0}=3$ o raio inicial da vizinhança e $\tau_{1}$ o número total de iterações.

Outro parâmetro utilizado na atualização de pesos sinápticos é a taxa de aprendizagem $\eta$, que inicia com valor unitário e é atualizada por:

$$
\eta(t)=\eta_{0} e^{\frac{-t}{\tau_{1}}}
$$

Após a definição dos parâmetros pode-se construir a equação para atualização dos pesos sinápticos $w_{j}$ :

$$
w_{j}(t+1)=w_{j}(t)+\eta(t) h_{i j}(t)\left(x-w_{j}(t)\right)
$$

que é aplicada ao neurônio vencedor e a todos os pertencentes à vizinhança topológica. A equação (9) move o vetor de peso sináptico em direção ao vetor de dado de entrada $x$, melhorando sua resposta ao apresentar dados semelhantes.

\section{Resultados}

Como definido anteriormente, fez-se uso de uma grade de neurônios quadrada com dimensão $5 \times 5$. Os dados foram apresentados de maneira aleatória para garantir a não existência de vício durante o processo de treinamento.

A seguir apresenta-se duas imagens, relativas ao dia 22/10/12.

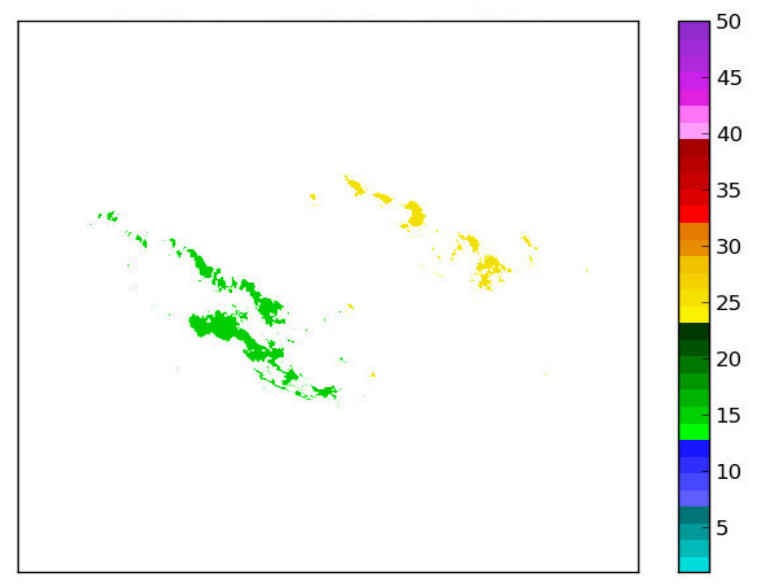

Figura 2: Agrupamento - 22/10/12 às 19h30

Observando a figura 2 verifica-se uma satisfatória separação dos dados em dois grupos principais, que nessa imagem são representados pelas cores verde e amarelo. 


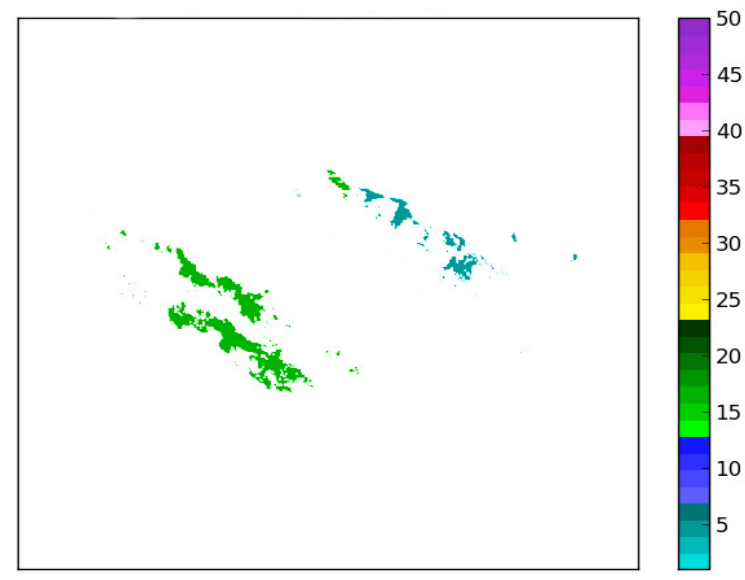

Figura 3: Agrupamento - 22/10/12 às 19h50

Na figura 3 nota-se também boa representação dos dados em grupos distintos, representados em verde e azul.

Tanto na figura 2 quanto na figura 3 as cores de cada grupo representam seu número de identificação, que será utilizado para acompanhamento, determinação de parâmetros e previsão de desenvolvimento e deslocamento futuros.

\section{Conclusões}

Ao final do trabalho verificou-se que a escolha das variáveis, refletividade e respectiva posição na matriz de dados, aliada à normalização dos dados, definição dos parâmetros e escolha das funções de atualização, gerou bons resultados. Em trabalhos futuros pretende-se utilizar outros dados meteorológicos, entre eles as alturas de refletividade máxima e de refletividades significativas (30, 45 e $60 \mathrm{dBZ}$ ) além de usar o resultado da clusterização afim de buscar melhorias em técnicas de previsão do desenvolvimento de eventos meteorológicos severos, através da escolha de limiares de intensidade e área mais condizentes com a região em estudo.

\section{Referências}

[1] A. C. P. de L. F. Carvalho and A. P. Braga and T. B. Lauremir, "Fundamentos de Redes Neurais Artificiais", DCC/IM, Rio de Janeiro, 1998.

[2] S. Haykin, "Redes Neurais: princípios e prática", Bookman, Porto Alegre, 2001.

[3] T. Kohonen, "Self-Organizing Maps", SPRINGER, New York, 1995.

[4] Y. Lu and T. Ma and C. Yin and X. Xie and W. Tian and S. Zhong, Implementation of The Fuzzy C-means Clustering Algorithm in Meteorological Data, International Journal of Database Theory and Application, 23 (2013) 1-18.

[5] R. E. Rinehart, "Radar for Meteorologists", Rinehart Publishing, Nevada, 2004.

[6] Z. Suraj and J. F. Peters and W. Rzasa, A Comparision of Different Decision Algorithms Used in Volumetric Storm Cells Classification, Fundamenta Informaticae, 51 (2002) 201214. 
[7] D. A. Vila and L. A. T. Machado and H. Laurent and I. Velasco, Forecast and Tracking the Evolution of Cloud Clusters (ForTraCC) Using Satellite Imagery: Methodology and Validation, Weather and Forecasting, 23 (2008) 233-245. 